limiting screening to women over 35 years, but as there has not been an overwhelming demand for the interpretation of smears these days are past.

Incidentally in our area, where the incidence of cervical cancer is falling, ${ }^{1}$ there have been no fewer than five women with overt clinical cervical cancer in the past two years who were multiparous and under 30 years of age.-I am, etc.,

\section{J. Elizabeth Macgregor. \\ Department of Obstetrics and Gynaecology, \\ REFERENCB}

1 Macgregor, J. E., Lancet, 1967, 2, 1296.

\title{
Preperitoneal Prosthetic Herniorrhaphy
}

SIR,-For some time it has been my view that the operative treatment of inguinal hernia as most commonly performed is illogical and has certain disadvantages which would be best avoided if acceptable alternatives were available. The object of the operation of separating the general peritoneal cavity from the hernial sac at the level of its neck is achieved by an approach through the inguinal canal which disrupts its anatomy unnecessarily, and a repair effected by approximating the conjoint tendon to Poupart's ligament seeks to unite muscle to ligament, utilizing and distorting tissues which by the very presence of the hernia have demonstrated their incompetence.

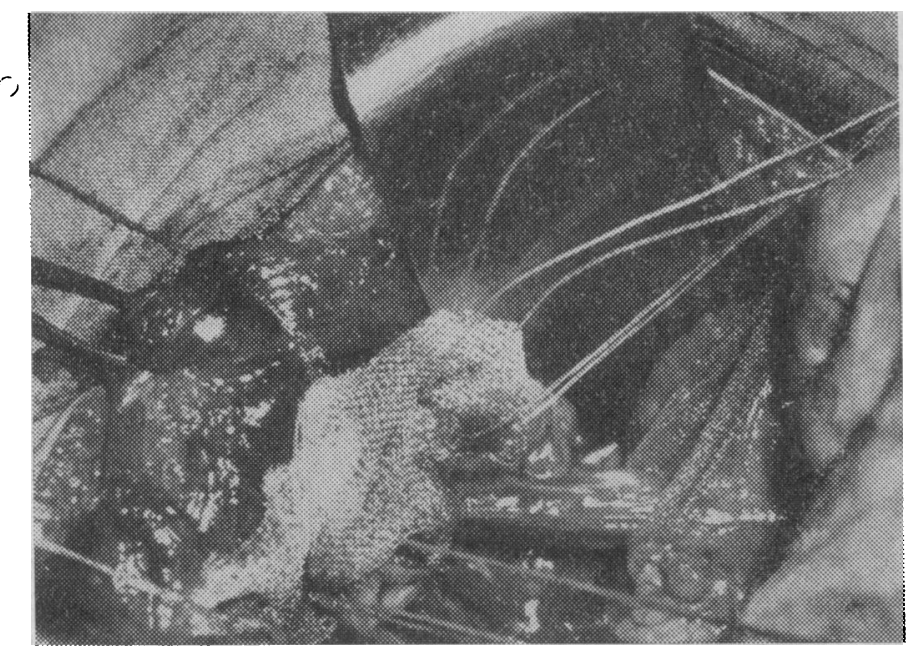

The prosthesis in position.

The first layer of the abdominal parietes to be transgressed in the development of a hernia is obviously the deepest layer, allegedly the fascia transversalis. It would seem logical, therefore, to reinforce the abdominal parietes at this level in order to prevent recurrent herniation; to do so in the plane of the conjoint tendon savours of "closing the stable door after the horse has bolted." I have not, however, had any confidence in a repair based on suturing the fascia transversalis, ${ }^{1}$ as this tissue has always seemed to me to be insubstantial, and I have as an alternative taken to reinforcing this layer with a prosthesis.

In order to overcome the aforementioned disadvantages of conventional hernia operations the following operative sequence has been evolved which I designate " preperitoneal prosthetic herniorrhaphy."

A midline suprapubic incision ${ }^{3}$ carried out under muscle-relaxant anaesthesia and an extraperitoneal approach to the inguinofemoral region enables a bilateral operation to be carried out if necessary and allows easy direct access to the hernial sac at its source. The hernial sac is either withdrawn into the abdominal cavity or divided at its neck and the defect in the peritoneum closed. A prosthesis of Marlex mesh $^{3}$ is sutured in position to the following points : the pubic tubercle, the periosteum of the superior pubic ramus, the ilio-pubic tract lateral to the internal inguinal ring, the anterior rectus sheath in the midline, and the deep aspect of the rectus muscle. By so doing the pros- the other above conditions. Prostatomegaly, however, was age dependent but the other conditions were not.

Mr. Bourke and Dr. Griffin do not mention the age-range of the patients, but it is clear from the elderly group above mentioned that the relation they detected between diabetes mellitus and benign prostatic hyperplasia does not obtain in men of advanced years. - I am, etc.,

$$
\begin{aligned}
& \text { Bydney, } \\
& \text { New'south Wales, } \\
& \text { Australia. } \\
& \text { 'Lake, B., f. chron. Dis., in press. }
\end{aligned}
$$

SIR,-We think we are bound to answer Dr. R. W. Lacey's letter (7 December, $p$ 642). We are aware of the shortcomings in the method used in our study (23 November, p. 492), and the final paragraph of the discussion stated that "It is possible that the high incidence of diabetes found in this study might in part be due to the stress of operation ; and glucose-tolerance-testing between the seventh and twelfth postoperative day when the patient was ambulant and eating a normal ward diet may have been insufficient precaution. Reduction of glucose tolerance with increasing age may also be a factor (Streeten et al., 1965 ; W.H.O. Expert Committee on Diabetes Mellitus, 1965; Butterfield, 1966). Further work is being undertaken to study these points."1-3 The signifiance of the last sentence seems to have been overlooked.

Despite the small series of 51 patients, it has confirmed the earlier findings of a retrospective study of 432 patients, who were submitted to operation for benign prostatic hyperplasia during a five-year period. An increased incidence of known cases of diabetes mellitus compared with normal populations was reported and substantiated by statistical analysis.

We are surprised that Dr. Lacey is unaware of the hypothesis that benign prostatic hyperplasia is one manifestation of a relative increase of oestrogens with advancing age, for it is not novel. The data for this were fully reviewed by both Teilum ${ }^{5}$ and Scott." Evidence of an increased oestrogen/androgen ratio has been provided by Marmorston et al." who reported that the oestrogen/ androgen ratio in 24-hour urinary collections from men with benign prostatic hyperplasia was increased compared with normal controls. It was this finding of abnormal oestrogen secretion which we quoted as further support for the hypothesis that benign prostatic hyperplasia is one manifestation of a relative increase of oestrogen secretion with advancing age. All these references were discussed in our paper.

We should, however, like to include the age distribution of our patients, which we apologize for omitting, together with the incidence of diabetes in each 10-year age group.

\begin{tabular}{c|c|c}
\hline $\begin{array}{c}\text { Age Group } \\
\text { in } \\
\text { Years }\end{array}$ & $\begin{array}{c}\text { No. of } \\
\text { Patients }\end{array}$ & $\begin{array}{c}\text { No. of Diabetics } \\
\text { (W.H.O. Expert } \\
\text { Committee 1965) }\end{array}$ \\
\hline $40-49$ & 2 & 1 \\
$50-59$ & 3 & 1 \\
$60-69$ & 23 & 10 \\
$70-79$ & 15 & 10 \\
$80-84$ & 3 & 1
\end{tabular}

SIR,-I have read with interest the paper by Mr. J. B. Bourke and In a recent morbidity survey of 713 men aged 70 years and over, ${ }^{1}$ the incidence of benign prostatomegaly was $20.9 \%$, of diabetes mellitus $1.9 \%$, of old myocardial lesions $27.1 \%$, and of recent myocardial infarct $10.2 \%$. In this series no associations or dissociations were detected between prostatomegaly and diabetes mellitus, nor between diabetes mellitus and the above conditions, nor between prostatomegaly and 
In answer to Dr. R. M. Robertson (7 December, p. 642) 8 out of 48 patients $(16.7 \%)$ who were not known diabetics showed glycosuria at some time prior to operation. However, Jackson et al. ${ }^{8}$ have reported that "glycosuria is commonly intermittent, even in untreated diabetics, is often absent when hyperglycaemia is present and is not a good screening test even after a glucose load." It was for this reason that we have not stressed glycosuria data. Since the data from this study became available it has increasingly become the clinical practice of the urological surgeons of this hospital to perform a glucose-tolerance test in the preoperative assessment of patients with prostatism.

The clinical observation that cardiovascular disorders are frequently associated with prostatic hyperplasia was made in the last century by Sir Benjamin Brodie," who wrote: "When the hair becomes grey and scanty, when specks of earthy matter begin to be deposited in the tunics of the artery, and when a white zone is formed at the margin of the cornea, at this same period the prostate gland usually-I might perhaps say invariably-becomes increased in size."-We are, etc.,

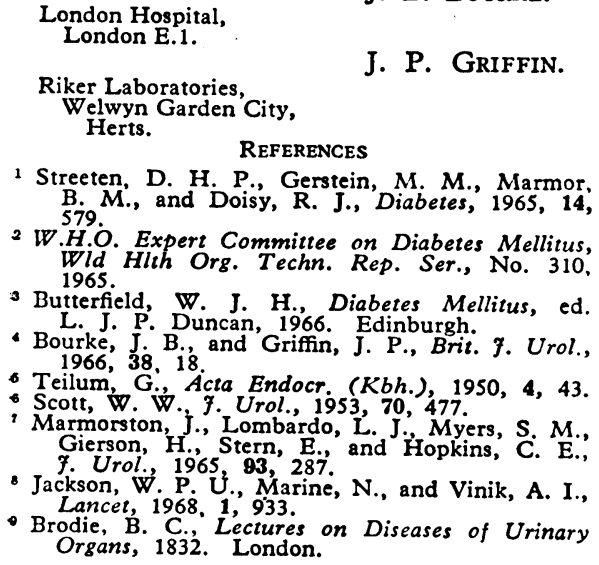

\section{Rejection on Medical Grounds}

SIR,-I recently saw a man who had been promised a job "subject to medical examination." After the examination he was told that the firm was extremely sorry that he could not be appointed because his blood pressure was above the limit laid down. He had never been ill, was symptom-free, had no cardiac enlargement, and his blood pressure varied between 180/105 and 160/95. He had set his heart on this job and was profoundly despondent about his future, fearing that as one firm had turned him down because of his blood pressure other firms would do the same.

I have advanced the view ${ }^{1}$ that leaving aside those such as bus drivers whose illnesses may endanger others-this kind of medical rejection is a monstrous injustice and should be forbidden by law. Those who are rejected because of creed, colour, race, or sex can at least appeal to some organization; those rejected medically are helpless.

As a profession we often complain about bureaucratic interference in the doctorpatient relationship. Yet some of us so distort that relationship that we harm the patient in the supposed interests of a prospective employer. Those who do so appear to observe the following modification of the Hippocratic Oath, "The regimen I adopt shall be for the benefit of my patients according to my ability and judgment, and not for their hurt or for any wrong, unless I am examining them on behalf of an employer, when the welfare of the patient shall count for nothing, and the interests of the employer shall be my sole concern."-I am, etc.,

\section{REFERENCB \\ 1 Todd, J. W., Lancet, 1965, 1, 797.}

\section{Prevention of Lumbar Puncture Headache}

SIR,-I note that Dr. H. Aziz and others (December 14, p. 677) have not found vasopressin to be effective prophylactically in postlumbar puncture headache. If I recollect correctly, it has been advocated that after lumbar puncture patients should lie prone for at least 24 hours, with one flat head pillow. The rationale appears to be that the spinal extension so produced helps to close the thecal puncture hole, while flexion tends to keep it open. I cannot quote my authority for this simple, safe, and rational suggestion, and would welcome any references.-I am, etc., J. DE SwIET.
East Glamorgan General Hospital,
Near Pontypridd.

\section{Neurogenic Intermittent Claudication}

SIR,-_" Intermittent claudication simply means intermittent limping, but it has become a term specifically applied to the interference with exercise caused by pain from an ischaemic muscle. Therefore one can designate a pain as intermittent claudication only if it is produced by exercise and relieved by rest."

This is the opening paragraph of an article in "Medicine Today" (7 December, p. 630) It implies that occlusive arterial disease of the legs is the sole cause of intermittent claudication. There is no reference to the neurogenic causes of intermittent claudication through narrowing of the lumbar spinal canal by a chronic disc prolapse or spondylitic bar. These have been so well described in your own, as well as in other journals, and can mimic the syndrome produced by chronic arterial disease so closely, that the differential diagnosis may depend upon myelography as much as upon aortography. ${ }^{1-6}$ When correctly diagnosed, neurogenic intermittent claudication can be completely relieved by laminectomy. Why therefore ignore it ?I am, etc.,

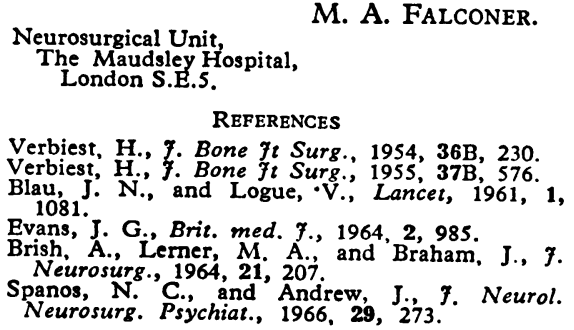

\section{Hyperpyrexia during Anaesthesia}

SIR,-It has been suggested by Dr. P. J. Horsey (28 September, p. 803) that malignant postoperative hyperpyrexia is related to postoperative halothane shivering, and indeed both conditions are associated with muscular rigidity of unknown cause and with anaesthesia. Furthermore, the degree of muscular rigidity occurring after halothane anaesthesia may be extreme.

We have made some observations on postoperative halothane shivering and agree with Dr. Michael Johnstone (19 October, p. 184) that methylphenidate (Ritalin) is effective in suppressing shivering occurring during emergence from a halothane anaesthetic.

In 1967 we were looking for some means of controlling the latter condition, and at that time the weight of the evidence seemed to support an association between a fall in body temperature during anaesthesia and the occurrence of shivering during the recovery phase. $^{1}$ The evidence for this was not conclusive, but we conducted a pilot trial using intravenous ethyl alcohol, which we have found effective in producing vasodilatation and suppressing shivering during controlled hypothermia.

We found alcohol of no benefit as a treatment given as a $15 \%$ solution in normal saline intravenously in doses of $40-50 \mathrm{ml}$. in six cases of established shivering; nor was it of benefit prophylactically. Of 16 patients given the same dose of alcohol as an intravenous infusion in the immediate postoperative period five developed marked shivering.

It has been reported that methylphenidate is effective in suppression of shivering from many causes. ${ }^{2}$ We gave it in a dose of $20 \mathrm{mg}$. intravenously to 34 patients who had developed shivering following a halothane anaesthetic. It was effective within two minutes in every case. Other effects noted included flushing, a rise in pulse and respiratory rate, occasional slight rises in blood pressure, arousal, and two instances of vomiting. The last effect had been related to speed of injection. ${ }^{2}$

The effect of methylphenidate on posthalothane muscular rigidity is so dramatic that it would be of interest to study its action in cases of malignant hyperpyrexia.-We are, etc.,

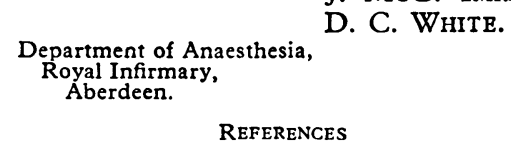

\section{Eating and Corticosteroid Levels}

SIR,-I have found that the concentration of 11-hydroxycorticosteroids (11-OHCS) in plasma of healthy men and women is usually quickly increased to up to $300 \%$ of its initial level by lunch. Less pronounced increases were found after glucose, alcohol, and unsweetened white coffee. Intravenous infusion of ethyl alcohol was recently reported to increase the plasma 11-OHCS (29 June, p. 804). 